\title{
Analisis Kemampuan Berpikir Intuitif Matematis Siswa dengan Self Efficacy Tinggi
}

\author{
Muhammad Tri Stio Ermawan \\ Pendidikan Matematika, STKIP Al Hikmah Surabaya \\ e-mail: trimuhammad3@gmail.com
}

\begin{abstract}
The students' mathematical intuitive thinking ability can be known from (1) students' ability to think reasonably, (2) students' ability to attribute their knowledge to newly encountered problems and (3) student's ability to generalize an example or concept to solve any mathematical problem faced. This study aims to analyze students' intuitive thinking skills that have different levels of self-efficacy. The research method used is descriptive qualitative. The results of this study show that students with self-efficacy have better mathematical intuitive thinking skills than students with low self efficacy.
\end{abstract}

Keywords: thinking ability; intuitive mathematical; self efficacy.

\begin{abstract}
The students 'mathematical intuitive thinking ability can be known from (1) students' ability to think reasonably, (2) students 'ability to attribute their knowledge to newly encountered problems and (3) students' ability to generalize an example or concept to solve any mathematical problem faced. This study aims to analyze students' intuitive thinking skills that have different levels of self-efficacy. The research method used is descriptive qualitative. The results of this study show that students with self-efficacy have better mathematical intuitive thinking skills than students with low self efficacy.
\end{abstract}

Keywords: thinking ability; intuitive mathematical; self efficacy.

\section{PENDAHULUAN}

Setiap orang diberikan bekal oleh Allah berupa kemampuan berpikir untuk mengahadapi segala jenis permasalahan yang ada dalam kehidupan. Lebih khusus kepada siswa yang dituntut untuk bisa menyelesaikan permasalahan yang ada pada pembelajaran di sekolah. Lebih khusus lagi pada mata pelajaran matematika yang menurut sebagian siswa masalah matematika sangat sulit untuk dipecahkan. Kemampuan berpikir yang dimiliki siswa bergantung pada bagaimana cara menggunakannya. Keberagaman ini menjadikan setiap siswa memiliki kemampuan yang berbeda dalam memecahkan suatu masalah matematika. Adakalanya siswa mampu memahami masalah matematika kemudian merencanakan strategi pemecahannya dengan segera pada saat siswa berhadapan dengan permasalahan tersebut, namun ada pula siswa yang membutuhkan waktu lebih lama untuk dapat menyelesaikannya. Menurut (Muniri, 2013) kemampuan siswa dalam memahami sekaligus menemukan strategi pemecahan masalah secara cepat dan tepat dipengaruhi oleh aktivias mental yang ditopang oleh kemampuan berpikir intuitif sehingga mampu memunculkan ide secara spontan, segera dan akurat.

Permasalahan matematika sangat beragam. Hal ini didasarkan pada konsep matematika yang tersusun secara hirarkis, terstruktur, logis, dan sistematis mulai dari konsep yang paling sederhana sampai pada konsep yang paling kompleks (Depdiknas, 2008). Dari konsep 
matematika tersebut diambil tiga jenis permasalahan matematika yaitu logis, sistematis dan bersifat kompleks. Permasalahan yang logis (masuk akal) berarti sesuai dengan fakta yang ada, hirarkis berarti adanya keterkaitan antara suatu konsep dengan konsep yang lain dan sitematis berarti terstruktur mulai dari konsep yang sederhana sampai pada konsep yang lebih umum. Siswa yang memiliki kemampuan berpikir intuitif akan mampu menyelesaikan masalah matematika dengan segera secara masuk akal, berdasarkan konsep lain yang berkaitan dan berdasarkan generalisasi dari contoh atau konsep (Fahtur, 2017). Proses pemecahan masalah merupakan kegiatan atau proses yang dilalui untuk menumukan solusi terhadap suatu kesulitan (Amir MZ dkk, 2017). Ketiga aspek itulah yang selanjutnya menjadi acuan bahwa seseorang mampu berpikir secara intuitif dalam menyelesaikan masalah matematika.

Faktor pemicu munculnya intuisi siswa dalam menyelesaikan masalah matematika memiliki keberagaman. Menurut Sa'o (2016) berpikir intutif dipengaruhi oleh feeling dan keyakinan yang kuat untuk memecahkan suatu masalah. Salah satunya dipengaruhi oleh tingkat efikasi diri (self efficayy) siswa. Semakin kuat efikasi diri siswa semakin kuat pula komitmen siswa terhadap tujuan yang ingin dicapai (Bandura, 1994). self efficacy dalam pembelajaran matematika diartikan sebagai penilaian tentang keyakinan diri seseorang terhadap kemampuannya untuk berhasil menyelesaikan masalah matematika (Risnawati dkk, 2017). Oleh sebab itu perbedaan keyakinan diri siswa menyebabkan karakteristik berpikir intutif siswa juga beragam. Sebagaimana pendapat Hamidah (2012), Amir MZ \& Risnawati (2015) bahwa keyakinan diri siswa sangat berpengaruh terhadap karakter berpikir siswa. Semakin tinggi efikasi diri maka siswa akan lebih mudah dalam menyelesaikan masalah matematika yang rumit atau spesifik sekalipun (Betz dan Hacket dalam Hamidah, 2012).

Terdapat perbedaan sikap antara siswa dengan self efficacy tinggi dan yang rendah. Siswa dengan self efficacy tinggi selalu bersemangat, tidak mudah menyerah dan selalu terlibat aktif dalam suatu kegiatan. Ketika mendapatlan tugas yang sulit, siswa dengan self efficacy tinggi akan berusaha dengan penuh keyakinan untuk dapat menyelesaikannya. Self-efficacy yang tinggi menjadikan siswa memiliki strategi yang bervariasi dalam menyelesaikan suatu masalah.Sekalipun seandianya ia gagal menyelesaikan masalah, ia akan mencobanya lagi sampai tujuan yang diinginkan tercapai. Sedangkan siswa dengan self-efficacy rendah cenderung malas untu berpikir dan mudah menyerah ketika menemui tugas-tuhas yang sulit (Bandura, 1997 \& Risnawati dkk, 2017).

Dari uraian di atas dapat diketahui bahwa keyakinan berpengaruh terhadap kemampuan berpikir serta tindakan seseorang. Masalah matematika yang berhubungan dengan berpikir intuitif tergolong sulit sehingga efikasi diri siswa harus tinggi agar mampu mengembangkan kemampuan berpikir intutif matematis siswa.

Gaya berpikir intuitif matematis dapat memicu kreativitas siswa dalam meyelesaikan masalah matematika (Usodo, 2011). Daya kreativitas siswa akan menjadikan siswa mempunyai cara-cara cerdas dalam menyelesaikan masalah matematika. Cara cerdas yang dimiliki siswa akan memberikan alternatif jawaban dari sebuah masalah secara cepat, singkat dan tepat (Sa'o, 2013). Adanya kreativitas siswa dalam menyelesaikan masalah matematika selaras dengan tuntutan kurikulum 2013 yang mengharuskan adanya kreativitas siswa dalam proses pembelajaran matematika Oleh karena itu siswa yang memliki kemampuan berpikir intuitif matematis akan meraih kesuksesan dalam belajar matematika.

Berdasarkan uraian-uraian di atas maka peneliti tertarik untuk menganalisis bagaimana kemampuan berpikir intuitif siswa dengan self efficacy tinggi. Penelitian ini semacam ini pernah dilakukan oleh Muniri (2013) dan Fahtur (2017). Perbedaan penelitian terletak pada objek tinjauannya. Peneliti pertama menggunakan kemampuan matematika siswa dan peneliti berikutnya menggunakan perbedaan jenis kelamin siswa, sedangkan dalam penelitian ini yang dijadikan tinjauan adalah self efficacy siswa. Indikator kemampuan berpikir intuitif matematif yang digunakan dalam penelitian ini berbeda dengan peneliti pertama yang mengacu pada karakter berpikir intuitif Fischbein (1987), namun serupa dengan penelitia kedua yang mengacu pada indikator berpikir intuitif menurut Sukmawa dan Wahyudin (2011). Adapun indikator yang 
digunakan yaitu, (1) siswa mampu menyelesaikan masalah dengan jawaban yang masuk akal, (2) siswa mampu menyelesaikan maslalah menggunakan pengetahuan dan pengalaman yang sudah dimilikinya dan (3) siswa mampu menyelesaikan masalah berdasarkan generalisasi dari contoh atau konsep. Ketiga permasalahan matematika tersebut akan mampu diselesaikan oleh siswa yang memiliki kemampuan berpikir intuitif matematis dengan segera dan akurat.

Hasil penelitian ini diharapakan dapat bermanfaat bagi beberapa pihak, diantaranya : (1) Bagi siswa agar dapat melatih kemampuan berpikir intuitif siswa. (2) Bagi guru agar dapat dijadikan referensi dan memberikan gambaran secara terperinci kemampuan berpikir intuitif matematis siswa dengan self efficacy tinggi guna menyusun rancangan pemebelajaran yang sesuai dengan keadaan siswa. (3) Bagi sekolah agar dapat dijadikan bahan pertimbangan dalam meningkatkan mutu pembelajaran matematika atau bidang studi lain. (4) Bagi peneliti lain agar dapat dijadikan referensi dalam penelitian yang berkaitan dengan kemampuan berpikir secara intuitif.

\section{METODE}

Penelitian ini termasuk penelitian kualitatif yang menganalisa kemampuan berpikir intuitif matematis siswa dengan self efficacy tinggi. Penelitian ini dilaksanakan pada tanggal 15 Desember 2017. Subjek dalam penelitian ini diambil 2 siswa kelas IX pada salah satu SMP di Surabaya, 1 siswa dengan self efficacy tinggi dan 1 siswa dengan self efficacy rendah sebagai pembanding. Penentuan tingkat self efficacy siswa dilihat dari instrumen angket penelitian yang telah diberikan kepada siswa. Setiap siswa diberikan Instrumen berupa lembar soal dan lembar kerja. Lembar soal berisi 3 soal tes kemampuan berpikir intuitif matematis, sedangkan lembar kerja berisi hasil jawaban siswa dari soal-soal tersebut. Selain data jawaban siswa secara tertulis juga diambil data secara lisan berupa rekaman suara siswa yang diperoleh dari hasil wawancara. Wawancara hanya dilakukan kepada subyek dengan self efficacy tinggi sedangkan Subjek kedua hanya dianalisis secara tertulis saja. Teknik pengumpulan data yang digunakan adalah studi dokumen dan rekaman suara siswa. Untuk lebih memahami alur dan analisis data yang dilakukan peneliti, perhatikan bahan berikut ;

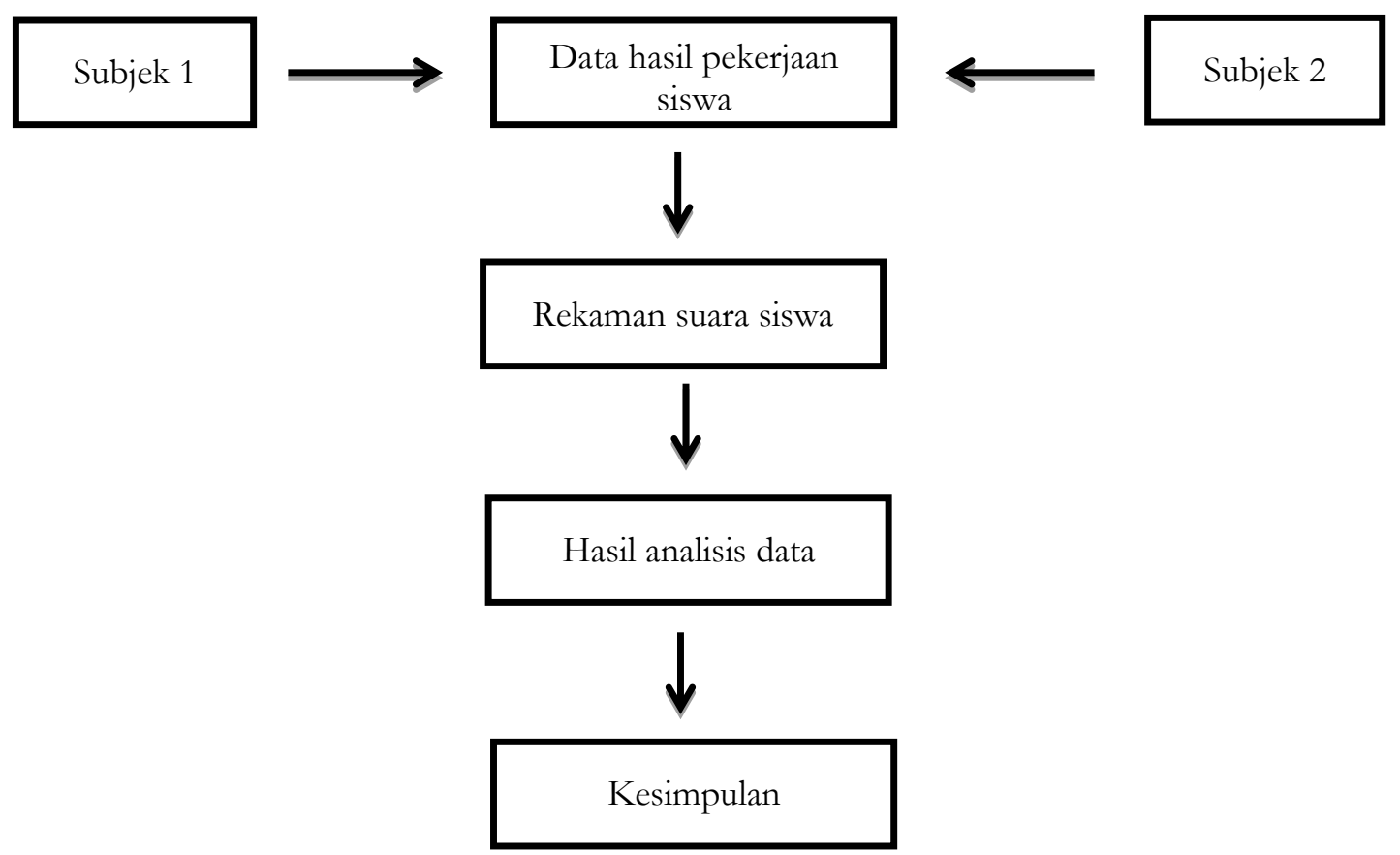

Bagan 1. Alur analisis data penelitian 
Data penelitian ini dianalisis secara kualitatif melalui proses reduksi data dengan menyeleksi, merangkum, mengelompokkan dan memilih data yang sesuai dengan penelitian, dilanjutkan dengan menyajikan data dan menarik kesimpulan (Sugiyono,2015).

\section{HASIL PENELITIAN}

Data hasil penelitian diambil dari dua siswa kelas IX di salah satu sekolah Surabaya yang masing-masing memeliki self efficacy tinggi dan rendah. Data yang diambil berupa lembar kerja dan rekaman wawancara siswa. Berikut akan diuraikan hasil pekerjaan siswa beserta pembahasannya terkait dengan kemampuan berpikir logis, berpikir dengan pengetahuan prasyarat dan berpikir dengan menggeneralisasi suatu konsep atau contoh.

\section{DISKUSI}

\section{Kemampuan Siswa dalam Berpikir Logis}

Soal 1 : Buatlah gambar segitiga dengan ukuran setiap sisinya adalah bilangan bulat.
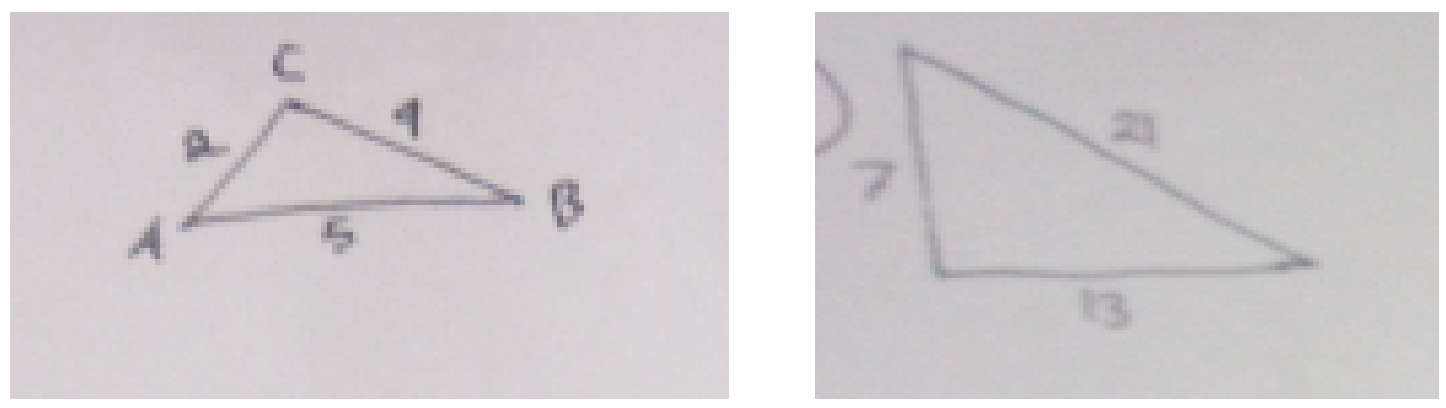

Gambar 1. Jawaban Siswa dengan self efficacy tinggi (SET) untuk soal 1. (kiri)

Gambar 2. Jawaban Siswa dengan self efficacy rendah (SER) untuk soal 1. (kanan)

Pada gambar 1 terlihat bahwa SET mampu membuat gambar segitiga dengan ukuran yang masuk akal. Segitiga yang dibuat adalah segitiga sebarang yang seluruh sudutnya adalah lancip dengan ukuran masing-masing sisinya berturut-turut adalah 2,4,5. Ukuran yang diberikan pada setiap sisi segitiga sesuai dengan konsep dan jenis segitiga yang dibuat oleh SET. SET memberi ukuran pada sisi terpanjang segitiga sesuai dengan konsep segitiga yaitu ukuran sisi terpanjang tidak mungkin melebihi atau sama dengan total ukuran pada kedua sisi lainnya. Ukuran yang dibuat SET juga tidak bertentangan dengan konsep segitiga lancip yaitu panjang kuadrat sisi terpanjang tidak boleh kurang atau sama dengan kuadrat jumlah panajang sisi-sisi lainnya.

Pada tahapan wawancara, peneliti memberikan beberapa pertanyaan berkaitan dengan soal 1 untuk mentriangulasi data hasil jawaban SET. Adapun cuplikan wawancara yaitu sebagai berikut.

P : Boleh tidak jika ukuran sisi terpanjang segitiga itu saya ganti menjadi tapi dengan gambar yang tetap?

SET : Tidak boleh pak.

$\mathrm{P} \quad$ : Mengapa?

SET : Itu tidak masuk akal pak.

$\mathrm{P} \quad$ : Mengapa?

SET : Jika ini dan ini saya gabungkan panjangnya jadi 7, kalau sisi yang ini lebih dari 7 kan tidak mugkin jadi segitiga (menunjuk sisi-sisi segitiga).

P : Oh.., begitu. Kalau yang ini panjangnya saya ganti 4 gimana?

SET : Itu juga tidak mungkin pak, kan ini segitiga lancip, jika yang panjang ini dikuadratkan harus lebih dari jumlah ini dan ini dikudratkan. 
Berdasarkan cuplikan wawancara di atas, diketahui bahwa SET menggunakan logikanya untuk membuat suatu segitiga beserta ukuran sisi-sisinya.

Pada gambar 2, SER membuat gambar segitiga dengan ukuran berturu-turut 7, 13, 21. Ukuran yang diberikan bertentangan dengan logika karena sisi terpanjang melebihi total panjang dua dua sisi lainnya. Kemudian dari gambar juga tampak tidak serasi antara gambar segitiga dengan perbandingan sisi-sisinya.Ini menunjukkan bahwa SER belum mampu menggunakan logikanya untuk memberi ukuran pada suatu segitiga.

\section{Kemampuan Siswa Menggunakan Pengetahuan Prasyarat}

Soal 2 : Sebuah segitiga siku-siku, panjang sisi-sisinya membentuk barisan aritmatika. Jika luas segitiga tersebut adalah 96 satuan, maka sisi terpendek adalah...

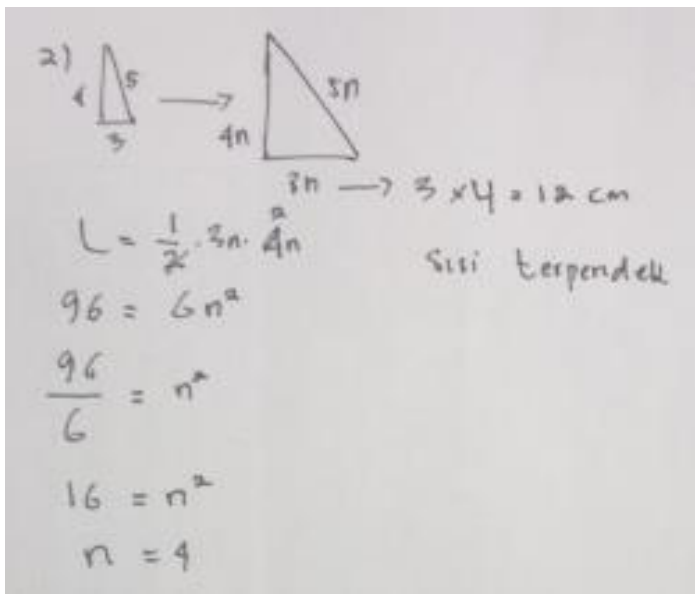

Gambar 3. Jawaban SET untuk soal 2

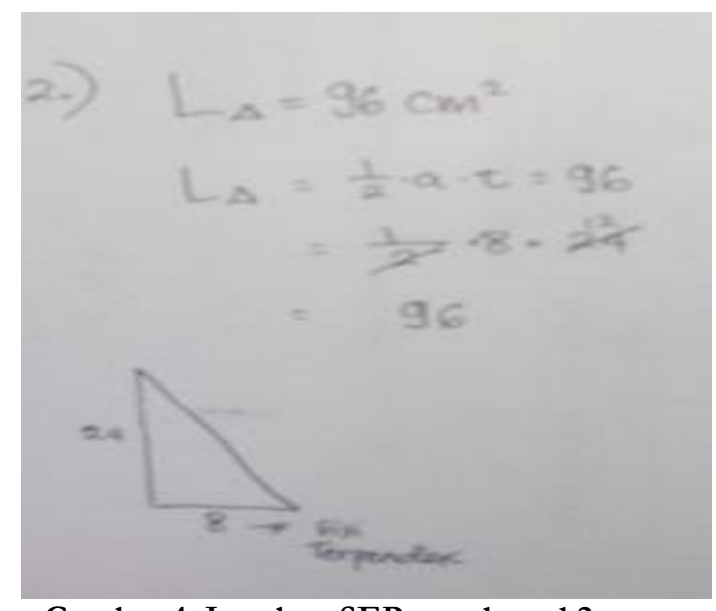

Gambar 4. Jawaban SER untuk soal 2.

Pada gambar 3, SET membuat segitiga siku-siku dengan ukuran 3,4,5 dan segitiga siku-siku yang lebih besar dengan ukuran berturut-turut 3n,4n, 5n. Dengan menggunkan rumus luas daerah segitiga $1 / 2 \times$ alas $\times$ tinggi, SET mencoba mencari nilai $\mathrm{n}$ dengan berdasarkan luas daerah segitiga yang diketahui yaitu $96 \mathrm{~cm}^{2}$. Setelah diketahui nilai $n=4$, SET berhasil menemukan panjang sisi segitiga terpendek yaitu $12 \mathrm{~cm}$ dengan cara mengalikan nilai n yaitu 4 dengan 3 .

Dari uraian di atas terlihat bahwa SET telah memiliki pengetahuan tentang triple phitaghoras yang dipadukan dengan pengetahuaannya tentang barisan aritmatika, sehingga SET memilih untuk menggambar segitiga siku-siku dengan pasangan triple phytaghoras 3,4 dan 5. SET mengetahui bahwa pasangan triple phytaghoras yang berkaitan dengan matematika memiliki beda yang sama. Setelah itu, SET menggambar segitiga siku-siku dengan ukuran sesuai kelipatan triple phytaghoras yaitu 3n,4n dan 5n. Hal ini menandakan bahwa telah memiliki pengetahuan tentang kesebangunan segitiga. Dari pengetahuan tersebut, SET mencoba mencari nilai $n$ dengan memanfaat luas segitiga yang telah diketahui ET. SET mampu memanfaat beberapa pengetahuan yang telah dimilikinya untuk menyelesaikan permasalahan matematika yang disajikan oleh peneliti.

Pada tahapan wawancara, peneliti memberikan beberapa pertanyaan berkaitan dengan soal 1 untuk mentriangulasi data hasil jawaban SET. Adapun cuplikan wawancara yaitu sebagai berikut.

P : Apakah sebelumnya kamu pernah mengerjakan soal yang seperti ini?

SET : Belum pak.

$\mathrm{P} \quad$ : Terus bagaimana kamu mengerjakannya?

SET : Sebelumnya saya sudah belajar tentang barisan aritmatika dan phitaghoras. Jadi meskipun belum pernah mendapatkan soal seperti ini, saya tidak kesulitan mengerjakannya. 
Dari cuplikan wawancara di atas benar bahwa SET menggunakan pengetahuan sebelumnya untuk menyelesaikan masalah yang baru diketahuinya. Hal ini memiliki kemiripan dengan temuan dalam penelitian Sa'o (2015) yaitu adanya pikiran siswa yang mampu memunculkan strategi pemecahan masalah pada saat siswa mulai memahami suatu masalah berdasarkan pengetahuan sebelumnya.

Pada gambar 4, SER terlihat belum sepenuhnya mampu memanfaatkan pengetahuan yang telah dimilikinya untuk menyelesaikan soal. SER menggunakan cara coba-coba untu menemukan ukuran sisi-sisi segitiga. SER menggunakan rumus mencari luas daerah yaitu $1 / 2 \times$ alas $\times$ tinggi kemudian ia mengganti alas dengan 8 dan tinggi dengan 24 sehingga hasilnya 96. Setelah SER menggambar segitiga siku-siku kemudian meletakkan angka-angka tersebut pada sisi-sisi segitiga. Terakhir barulah SER menyimpulkan bahwa sisi terpendek adalah $8 \mathrm{~cm}$. Dalam cuplikan wawancara SER mengatakan bahwa dia tidak tahu bagaiman menentukan sisi-sisi segitiga sesuai dengan barisan matematika. Atas dasar itu sehingga SER menggunakan cara coba-coba untuk menentukan sisi terpendek pada segitiga siku-siku yang diminta oleh soal.

\section{Kemampuan Siswa Melakukan Generalisasi dari Contoh atau Konsep}

Soal 3 : Adit memiliki batang-batang korek api berukuran $5 \mathrm{~cm}$. Jika adit membuat sebuah segitiga samasisi dari batang-batang korek api tersebut maka keliling segitiga tersebut $15 \mathrm{~cm}$. Jika ia membuat dua segitiga, maka jumlah keliling keduanya $30 \mathrm{~cm}$ dan jika ia membuat 3 buah segitiga, maka jumlah keliling ketiganya $45 \mathrm{~cm}$. Jelaskan berapa banyak batang korek api yang dibutuhkan adit untuk membuat $n$ buah segitiga.

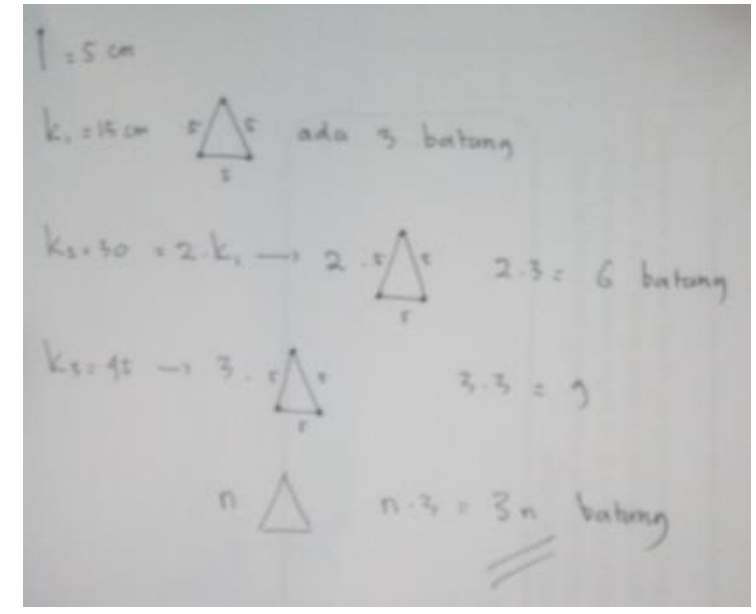

Gambar 5. Jawaban SET untuk soal 3

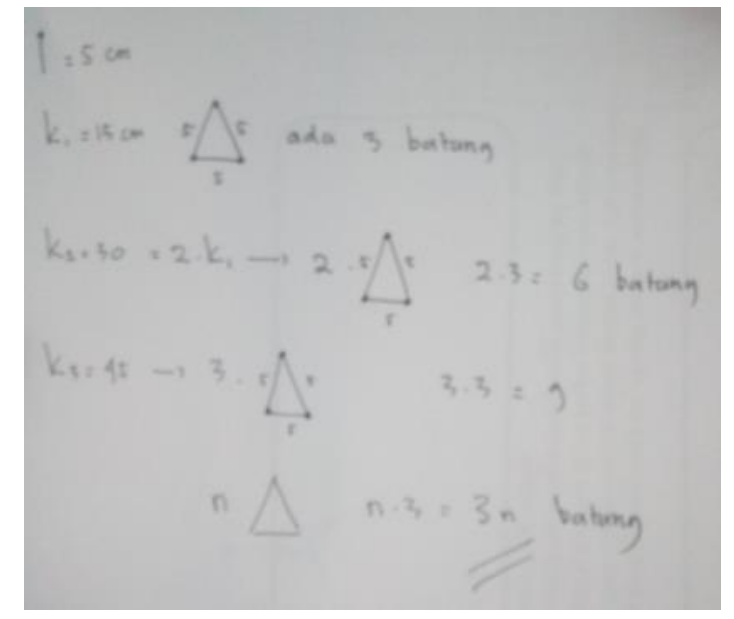

Gambar 6. Jawaban SER untuk soal 3

Pada soal yang ke tiga, SET dan SER berhasil menjawab soal dengan benar. Perbedaan terletak pada cara yang digunakan oleh keduanya. SET memiliki kemampuan generalisasi yang ditunjukkan oleh gambar-gambar segitiga yang dipadukan dengan aturan keliling segitiga. Dengan cara itu SET berusaha untuk menemukan pola yang digunakan untuk mencari banyak batang korek api pada n segitiga. pada saat wawancara SET ditanya mengapa kamu menggunakan gambar untuk bisa mendapatkan hasil tersebut. SET menjawab bahwa gambar tersebut untuk menunjukkan bahwa segitiga pertama, kedua dan ketiga yang dibuat oleh Adit memiliki ukuran sisi yang sama yaitu masing-masing $5 \mathrm{~cm}$ yang mana sama dengan panjang batang korek api yang digunakan untuk membuat segitiga tersebut. Lebih lanjut ia mengatakan bahwa hal itu berarti dibutuhkan 3 batang untuk satu segitiga, 6 batang untuk 2 segitiga dan 9 batang untuk 3 segitiga. Selanjutnya SET ditanya tentang bagaimana ia menyimpulkan bahwa untuk membuat $\mathrm{n}$ segitiga dibutuhkan 3n. SET menjawab bahwa dengan melihat ketiga segitiga yang diketahui masingmasing ukurannya, maka saya mengetahui bahwa dibutuhkan tiga kali segitiga untuk membuat 
segitiga yang dinginkan. Sedangkan SER hanya menggunakan satu gambar segitiga sama sisi yang disisipi masing-masing sisinya dengan panjang $\mathrm{n}$ kemudian menggunkan aturan keliling segitiga SER menjumlah setiap panjang sisi segitiga sehingga menjadi $3 \mathrm{n}$. Dalam kutipan wawancara SER mengatakan bahwa segitiga yang banyak dapat diubah menjadi satu segitiga dengan ukuran yang lebih besar dengan panjang sisi adalah gabungan dari semua sisi segitiga yang dibuat sebelumnya, sehingga kalau ada n segitiga berarti bisa dibuat menjadi satu segitiga dengan ukuran setiap sisinya adalah n. Lebih lanjut SER diberikan pertanyaan bagaima jika Adit akan membuat 5 segitiga, berapa batang korek api yang dibutuhkan untuk membuanya. Dalam pertanyaan tersebut SER mulai merasa bingung yang ditunjukkan oleh sikapnya yang mulai menggaruk-garuk kepalanya. SER tidak bisa langsung menjawab melainkan ia harus menggambar segitiga terlebih dahulu kemudian setiap sisi diberi ukuran 15. Sebelum melanjutkan pekerjaannya peneliti meminta SER untuk membuat 5 segitiga dengan ukuran masing-masing sisinya adalah $5 \mathrm{~cm}$, kemudian berdasarkan pernyataan SER peneliti memintanya untuk mengubahnya menjadi satu segitiga. Ternyata segitiga yang dibuat ukuran sisinya adalah 25 . Hal berarti pernyataan S2 tentang hubungan panjang sisi segitiga dengan banyak segitiga tidak tepat.

Berdasarkan paparan data dan temuan penelitian di atas, dapat disimpulkan bahwa siswa dengan self-efficacy tinggi mampu berpikir intuitif matematis dibandingkan siswa dengan self-efficacy rendah. Adapun kemampuan berpikir intuitif yang di maksud yaitu meliputi kemampuan berpikir logis, mengkonstruk pengetahuan awal dan menggeneralisasi suatu contoh atau konsep. Diantara ketiga indikator tersebut, indikator berpikir intuitif matematis yang paling tampak pada siswa adalah kemampuan mengunakan pengetahuan dan pengalaman dalam menyelesaikan masalah matematika. Hal ini tampak pada jawaban SET baik tulisan maupun lisan yang selalu mengacu pada pengetauan yang telah didapat sebelumnya. Sebagaimana pendapat Krulik. Stephen \& robert E. Reys (1980) yang menyatakan bahwa pengetahuan dan pengalaman berpengaruh terhadap kemampuan menyelesaikan masalah dengan segera (berpikir intutif).

\section{SIMPULAN}

Hasil penelitian ini menunjukkan bahwa siswa dengan self efficacy memiliki kemampuan berpikir intuitif matematis yang lebih baik daripada siswa dengan self efficacy rendah. Untuk penelitian selanjutnya harapanya menggunakan subjek yang lebih dari dua dan intrumen tes yang bervariasi serta wawancara yang lebih mendalam agar lebih memahamai bagaimana siswa menemukan alur jawabannya.

\section{DAFTAR PUSTAKA}

Amir MZ, Z \& Risnawati. (2015). Psikologi Pembelajaran Matematika. Yogyakarta: Aswaja Pressindo

Amir MZ, Z \& Wahyudin \& Turmudi. (2017). Metacognition Think Aloud Strategies In Setting Cooperative Think-Pair-Share/Square to Develop Student's Math Problem Solving Ability (Comparative Study on Students of Madrasah Tsanawiyah Boarding/non-Boarding school in Pekanbaru). Advances in Social Science, Education and Humanities Research (ASSEHR), volume 57. ISSN 2352-5398

Bandura, A. (1994). Self-Efficacy. In V. S. Ramachaudran (Ed), Encyclopedia of human begaviour (vol. 4, pp. 7181). New York: Academic press. (Reprinted in H. Friedman (ed, Encyclopedia of mental healt. San Diego: Academic press, 1998).

Bandura, A. (1997). Self-Efficacy, The Exercise of Control. New York: W.H. Freeman and Company Ahmad, F. A. (2012).

Depdiknas, (2008).Kamus Besar Bahasa Indonesia”, Gramedia Pustaka Indonesia

Fahtur, S.2017. Pengembangan Instrumen Dan Kemampuan Berpikir Intuitif Matematis.

Fischbein, E. (1987). Intuition in Science and Mathematics. Israel : School of Education Tel Aviv University.

Hamidah, 2012.Pengaruh Self Efficacy Terhadap Komunikasi Matematik.Bandung: STKIP Siliwangi.

38 Suska Journal of Mathematics Education, Vol. 4, No. 1, 2018 
Krulik. S \& Robert E. R. (1980). Problem Solving in School Mathematics, 1980 Yearbook. Reston, VA: NCTM, Inc.Hanapi, M. S. (2013).

Muniri, (2013). Karakteristik Berpikir Intuitif Siswa Dalam Menyelesaikan Masalab Matematika. (Makalah dipresentasikan dalam Seminar Nasional Matematika dan Pendidikan Matematika FMIPA UNY Yogyakarta, 9 November 2013).

Risnawati, Amir MZ., Z \& Kartika, Y. (2017). The Influence of the Implementation of Think-Pair-Share Method and Self Efficacy toward Students' Mathematical Problem Solving Skills at SMPN 21 Pekanbaru. SIMaNIs (Seminar Nasional Integrasi Matematika dan Nilai Islami) Proceeding Vol.1, No.1, July 2017, pp. 492-495 p-ISSN: 2580-4596; e-ISSN: 2580-460X

Sa'o, S,. (2013). Intuisi Siswa Pada Penyelesaian Masalab Matematika Divergen Topik Segitiga. KNPM V, Himpunan Matematika Indonesia.

Sa'o, S. (2015). Berpikir Intuitif Siswa Dalam Pemecahan Masalah Matematika. Disertasi, Program Studi Pendidikan Matematika.

Sa'o, S. (2016). Berpikir Intuitif Sebagai Solusi Mengatasi Rendahnya Prestasi Belajar Matematika. http://jrpm.uinsby.ac.id.

Sugiyono. (2015). Metode Penelitian Kualitatif, Kuantitatif dan R\&D. Bandung: ALFABETA.

Sukmawa, A., \& Wahyudin. 2011. A Teaching Material Development for Developing Students Intuitive Thingking Throub Raect Contextual Teacbing Approach. Mat Stat.S

Usodo, B. (2011). Karakteristik Intuisi Siswa Sma dalam Memecahkan Masalah Matematika Ditinjau dari Kemampuan Matematika dan Perbedaan Gender. Surakarta: Perputakaan FKIP UNS.Hanapi, M. S. (2013). 